\title{
sciendo
}

Int. J. of Applied Mechanics and Engineering, 2020, vol.25, No.2, pp.130-141

DOI: $10.2478 /$ ijame-2020-0025

\section{NUMERICAL ANALYSIS OF DEFORMATION AND FLOW IN THE PROXIMAL AREA OF THE URETHRA}

\author{
R. RUDYK, M. MALINOWSKI, A. MACKIEWICZ* and R. BEDZINSKI \\ University of Zielona Góra \\ Szafrana 4 str., 65-516 Zielona Góra, POLAND \\ E-mail: a.mackiewicz@ibem.uz.zgora.pl
}

\author{
A. NOSZCZYK-NOWAK, J. SKONIECZNA and J.P. MADEJ \\ Wroclaw University of Environmental and Life Sciences \\ Wroclaw, POLAND
}

\begin{abstract}
Pathological conditions of a male urethra, including fibrosis, have a mechanical background along the entire length of the urethra. They may be caused by excessive deformation of the urethra locally or globally. The condition of prolonged overload causes abnormal tissue remodelling and, consequently, the formation of a thick layer of scar tissue differentiated from the connective tissue of the urethra. This tissue, which has higher mechanical properties, is not highly deformable and therefore, causes a decrease in the diameter of the urethra, which results in conditions that disturb the natural flow of urine. In this paper, it was decided to determine the deformation conditions in the proximal part of the urethra. The study was conducted in three main stages. Transverse sections of the animal urethral tissues were prepared in order to examine mechanical properties and perform histological examinations. On the basis of these examinations, material models which fitted best for the experimental results were sought. Material constants of the Mooney-Rivlin material model with the best fit ratio were determined for further research. On the basis of histological photographs, a geometrical and numerical model of the urethra was developed. The urethra was tested in a flat state of deformation. The strain and stress fields of the Caucha tensor were examined. The methodology of testing the dynamics of the urine flow in the highly deformable urethra was proposed. This is important for the analysis of the influence of at excessive pressure on pathological tissue remodelling leading to fibrosis.
\end{abstract}

Key words: urethra, stress-strain characteristic, FEM, CFD, urinary flow.

\section{Introduction}

In the human body, there are several canal systems in which there is a continuous flow of gases or liquids. These include the circulatory system, lymphatic system, respiratory system or urinary tract [1-4]. Since William Harvey confirmed that the blood was actually in continuous circulation and was transported by a series of vessels, the most frequently described tabular system has been the cardiovascular system and its discontinuities of flow caused by changes in the structure of the arteries or the functioning of the heart as a pump [5]. Another particularly important issue is the lower urinary tract, where the stress characteristics as well as non-linear deformations and complex environment affect the possibility of pathological states [6].

Disorders related to changes in the continuity of the urine flow are increasingly considered a significant problem that affects the physical, psychological, social and economic well-being of the patients and represents a significant economic charge to health and social services [7]. The symptoms associated with the urethral stenosis have complex causes. Most frequently, they result from irritation of the urinary tract as a result of endoscopic examination, developing inflammation or prostate overgrowth [8]. It is worth noting that the structure of the urethra as well as the flow conditions vary along its entire length. The highest liquid

\footnotetext{
To whom correspondence should be addressed
} 
pressure values are found in the extreme parts (proximal and distal parts), where urine gains significant velocity and where the urethral lumen diameter is narrowed naturally, e.g. at the level of the prostate $[9,10]$. It should be emphasised that most of the pathologies are mechanically related to local or global change of the strain and stress fields, which leads to abnormal tissue remodelling at the site of temporary or constant application of forces to the urethra tissue. Improper remodelling of the urethra wall tissues leading to fibrosis (sclerotic tissue build-up) results in additional narrowing caused by the increased urine flow velocity and increased stress in the urethra tissues.

The most frequently observed clinical symptoms of this condition include disorders of continuous urination (intermittent stream, decreased urine flow, frequent urination, nocturia, i.e. the need to urinate at night), the feeling of incomplete emptying of the bladder or complete stopping of micturition $[11,12]$. These symptoms cause significant discomfort to the patient's life as well as irreversible effects in the form of, among others, complete stopping of flow or initiation of cancerous proliferation.

In order to restore normal physiological conditions, a preventive treatment with pharmaceuticals is used. This is not always sufficient, therefore, catheters and balloons are often inserted into the urethra, mechanically expanding its lumen. However, the interference resulting from their introduction may cause secondary inflammation and fibrosis. Surgical procedures, including the introduction of implants, are used in the extreme cases of urethral stenosis which occur more and more commonly. Development of the implant (stent) design, material selection and implantation technique are important for the healing and regeneration of the urethral tissues [13-16] Therefore, there is a need to develop optimal methods including analysis of the basic properties of soft tissues and systems for testing of the flow conditions in the mammals bodies.

Diagnostics of the urine flow conditions in the urethra with advanced stenosis and methods of prevention and treatment are still insufficient. The use of computational methods in the study of deformation states of hyper-elastic solids (FEM - finite element method) [13] and computational fluid dynamics (CFD) enable non-invasive determination of the stress and strain states and the urine flow in the urethra $[17,18]$. The coupling of the two physical environments makes it possible to analyse the fluid-structure interaction (FSI) as did Zheng et al., 2015 or Bonfanti et al., 2018, for example [19, 20]. Reconstruction of the urethral lumen geometry itself and separation of the individual tissues that are part of the histological structure is a difficult but at the same time necessary issue in order to declare the real boundary conditions. Imaging methods for urethra, such as computed tomography, magnetic resonance imaging [21, 22] and ultrasonography $[23,24]$ seem to be insufficient for the evaluation of three-dimensional(3D) tissue geometry with the isolated lumen of the urethra, which, in most published papers, is simplified to the shape of a duct with a circular or oval cross-section $[25,26]$. This is one of the reasons why it is impossible to obtain the correct urine flow conditions. Histological examination allows to obtain the exact dimensions and volume content of the tissues that are a part of such organ as urethra [27-30]. These studies also allow to determine the real state of the tissue (inflammatory, fibrosis or normal), which affects different, non-linear mechanical properties and conditions of the urethra structures reconstruction and change the distribution of strain fields [31].

Irregular shape of the urethra lumen, diverse, non-homogeneous tissue structure and forced conditions resulting from heterogeneous urine flow create a complex calculation problem for the urethra deformation conditions. Solving this problem is important in order to explain the phenomenon of the fibrosis conditions in the urethra and to develop new treatment methods of the pathological conditions. Therefore, the aim of this paper is to understand the mechanism of the urethra deformability in the proximal part of the urethra, the changes in the urethra under the influence of the urine pressure during micturition as well as to identify the geometric conditions and flow as the factors causing fibrosis of the urethra.

\section{Materials and methods}

The experimental material consisted of 14 male New Zealand White rabbits with a body weight of 2.1-3.0 kg (Approved by the Bioethics Committee No 1/2017). The development of the numerical model was based on the results of the histological examination. On this basis, their structure was examined, their condition was evaluated and then geometric and numerical models of the urethra cross-section in its 
proximal part were defined. The real stress-strain characteristics of the urethra, which accurately reflected its functions, structure and mechanical properties were experimentally investigated. Histological imaging made it possible to reconstruct the lumen geometry of the urethra and its layered tissue structure. An important modelling step was the introduction of the actual boundary conditions and internal load (pressure) resulting from urine flow. In such tests it is important to adopt an appropriate material model. Based on the results of the experimental research of transverse sections of the urethra being stretched in the radial direction, the mechanical properties were determined and on their basis a model of hyper-elastic Mooney-Rivlin 5 parametric material with the $R 2>0.82$ fit was selected. Static tensile tests of 5 urethra sections in the proximal part were performed using the Zwick/Roell EPZ 005 testing machine. During the study, taking into account the variable geometry of the urethra as well as its tissue structure and differences in mechanical properties, the organ was divided into two segments (from the bladder side and the urethra opening). A similar practice was introduced by Natali et al. 2016 in his study by dividing the urethra into proximal and distal parts [6]. The urethra samples were photographed on the test stand due to their high softly and in order to determine their dimensions and surface area. Soft tissues, especially those with collagen structure, including the urethral tissues, require this procedure [31]. Using Zaiss AxioVision software, the images were analysed before the tensile test to avoid the error associated with the initial deformation of the tissue material in contact with the measuring tools. The samples were stretched in the radial direction and with the use of a specially developed grip [6]. This allowed to recreate the conditions of the urethra stretching during the urine flow, which caused expansion of the internal lumen of the urethra with the internal pressure evenly distributed on the walls. The tensile test was carried out under the following conditions: air temperature 23.5 ${ }^{\circ} \mathrm{C}$, humidity $50 \%$, test velocity $15 \mathrm{~mm} / \mathrm{min}$. The force-elongation relationship curves obtained from the tensile test were the basis for further analyses. Knowing the dimensions of the specimens, the data obtained were converted into stress and strain values in the STATISTICA software, where the regression curves $(p=0.95$ and $R 2>0.82)$ and Young's module for the individual strain ranges were also determined. The mathematical model of the urethral material was determined in Ansys 16.2 software. Stress-strain charts proved that the urethra of the White New Zealand rabbit showed the features of hyper-elastic material [6, 22, 36, 32]. The stress-strain curve was adjusted to the existing material models, among others: Mooney-Rivin, Ogden and Arruda-Boyce (Fig.1a). Similar models in their work were used in [6, 25, 26, 34]. The ArrudaBoyce model showed low conditions of fitting to the experimental results. $(R 2>0.35)$. The analysis of the other fitting results for the adopted urethral tissue models showed that 2-, 5- and 9-parameter Mooney-Rivlin (MR) models constituteda good fitting of experimental results to the material model (Tab.1). The MooneyRivlin 5-parameter model had the best fit. The use of this material model in a discreet urethra model allowed a good description of non-linear mechanical properties (Fig.1b).
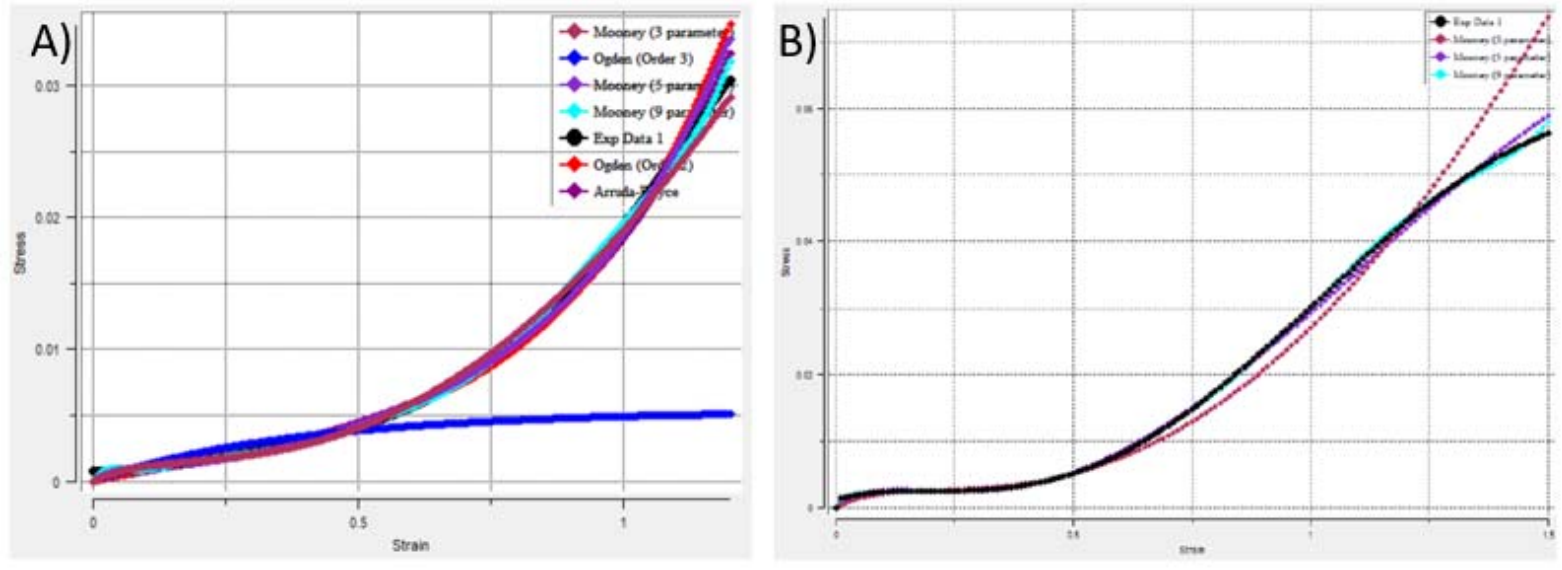

Fig.1 a) Fitting curves to experimental results (stress-strain) for selected models of hyper-elastic materials, b) Fitting curves of Mooney-Rivlin material models - urethra proximal part. 
The strain energy density for 5-parametres hyper-elastic model of Mooney-Rivlin $W_{(5)}$ is defined by the equation [35]

$$
\begin{aligned}
& W_{(5)}=C_{10}\left(I^{\prime}{ }_{1}-1\right)+C_{01}\left(I^{\prime}{ }_{2}-1\right)+C_{20}\left(I^{\prime}{ }_{1}-l^{2}\right)+ \\
& +C_{02}\left(I^{\prime}{ }_{2}-1\right)^{2}+C_{11}\left(I^{\prime}{ }_{1}-1\right)\left(I^{\prime}{ }_{1}-1^{2}\right)+\frac{1}{d} J-1^{2}
\end{aligned}
$$

Cij - material constants calculated by fitting to the experimental strain-strain curve, $I_{1}^{\prime}, I_{2}^{\prime}$ - invariants of Green deformation tensor defined.

Table 1. Material constants for the 5-parameters Mooney-Rivlin material model.

\begin{tabular}{rrrrrr} 
Material constant & $\mathrm{C} 10$ & $\mathrm{C} 01$ & $\mathrm{C} 20$ & $\mathrm{C} 11$ & $\mathrm{C} 02$ \\
\hline Value $[\mathrm{MPa}]$ & -8.680 & 9.229 & 29.675 & -87.309 & 69.543
\end{tabular}

The histological examination allowed to determine the type and volume of the tissues in the White New Zealand rabbit urethra. Tissue preparations were stained with haematoxylin and eosin [27, 28, 29, 30]. The geometry of the lumen urethra and the thickness of the individual tissue layers were determined using the image analysis in Axio Vision LE 4.8.2 software (Fig.2). Separated tissue structures can be presented in the following ranges: urothelium $70-100 \mu \mathrm{m}$ thick, loose connective tissue $65-290 \mu \mathrm{m}$ thick. The muscularis is thick and consists of three layers where the external and internal layers are longitudinal, while the middle layer is circular $(770-1030 \mu \mathrm{m})$. Due to the scale of preliminary studies, the tissue structures in the model were simplified and the mechanical properties for the urethra averaged.

On the basis of the histological images (example in Fig.2a), a geometrical model of the cross-section of the urethra was developed (Fig.2b The geometric model was used to generate a discrete model where the finite element grid in Ansys 16.2 was locally thickened in the direction of the urethra lumen. Due to the expected large deformation of the areas near the urethra lumen, it was necessary to obtain a numerical solution. In the numerical model, the element of the Plane 183 type was used, which had, depending on its shape, 6-8 nodes, and each node had two displacement degrees of freedom. The task was solved in plane state of deformation. In order to obtain the solution, the numerical model of the urethra was supported as shown in Fig.2b. Supports on the circumference of the urethra were fixed in three nodes (1. node $u_{x}=0$; 2. node $u_{y}=0 ; 3$. node $\left.u_{x}=u_{y}=0\right)$.

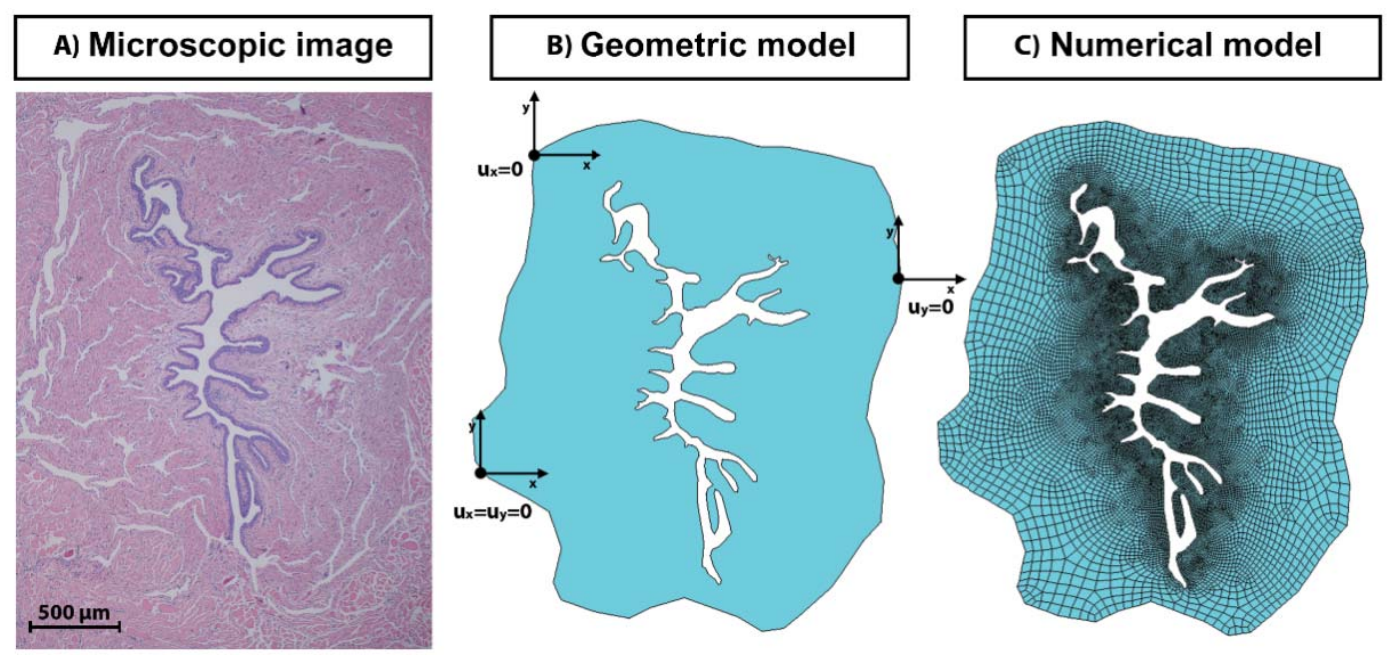

Fig.2. Steps in the construction of the urethra numerical model. 
The mean value of Young's modulus, which was determined during the experimental studies, was $0.07 \mathrm{MPa}+/-0.015 \mathrm{MPa}$.

In case of the flow dynamics studies, as a boundary issue and used in the numerical analysis, CFD can be described by constitutive equations. The flow of fluids inside a high deformation duct is difficult to realise. The basis for developing of the final flow equation is the development of the Navier-Stokes equation [34].

$$
\rho \frac{\partial v_{i}}{\partial t}+\rho v_{j} * \frac{\partial v_{i}}{\partial j}=-\frac{\partial \rho}{\partial x_{i}}+\mu \frac{\partial}{\partial j}\left(\frac{\partial v_{i}}{\partial j}\right)+\rho f_{i}, \frac{\partial v_{i}}{\partial x_{i}}=0 \quad t \in(0, T), x \in \Omega
$$

Using Galerkin's method to solve the hydrodynamic flow problem, we obtain a constitutive equation in its final form

$$
\begin{aligned}
& \int_{\Omega} \rho \frac{\partial v_{i}}{\partial t} \delta v_{i} d x+\int_{\Omega} \rho v_{j}^{*} \frac{\partial v_{i}}{\partial x_{j}} \delta v_{i} d x-\int_{\Omega} \rho \frac{\delta \partial v_{i}}{\partial x_{i}} d x+\int_{\Omega} \mu \frac{\partial v_{i}}{\partial x_{j}} \frac{\delta \partial v_{i}}{\partial x_{j}} d x= \\
& =\int_{\Omega} \rho f_{i} \delta v_{i} d x-\int_{\partial \Omega_{2}}\left(\mu \frac{\partial v_{i}}{\partial \rightarrow}-\rho n_{i}\right) \delta v_{i} d x, \\
& \int_{\Omega} \frac{\partial v_{i}}{\partial x_{i}} \delta d x=0 .
\end{aligned}
$$

The equation above represents a reduced form of description of the non-compressible fluid flow through a tubular object in the form of an elastic urethra, taking into account the non-linearity of the material and turbulence of the fluid flow. Equation (2.4) describes the behaviour of male urethral walls in deformable conditions, which is presented in the form of a modified Newton-Raphson equation solved by iterative method

$$
\begin{aligned}
& \int_{\sigma_{V}} \delta\left(\Delta_{0}^{t} \varepsilon_{i j}^{L}\right)^{(k)}{ }_{0} E_{i j k l}\left(\Delta_{0}^{t} \varepsilon_{k l}^{L}\right){ }^{(k)} d^{0} V+\int_{{ }^{O}} \delta\left(\Delta_{0}^{t} \varepsilon_{i j}^{N L}\right)^{(k)}{ }_{0}^{t} S_{i j} d^{0} V= \\
& =\delta^{t+\Delta t} W-\int_{o V} \delta\left(\Delta_{0}^{t} \varepsilon_{i j}^{L}\right)^{(k-1)}{ }_{0}^{t} S_{i j}^{(k-1)} d^{0} V, \\
& { }^{t+\Delta t} u_{i}^{(k)}={ }^{t+\Delta t} u_{i}^{(k-1)}+\Delta u_{i}^{(k)},{ }^{t+\Delta t} u_{i}^{(0)}={ }^{t} u_{i} .
\end{aligned}
$$

In order to simplify the above equations, the inner lumen of the urethra was loaded with a linearly increasing pressure. The maximum urinary pressure was $4 \mathrm{kPa}[26,32]$.

In the literature, this value appears many times, hence, it is possible to compare the results obtained by other authors in the experimental and model studies [23, 32, 37-39]. In the scope of the CFD flow dynamics analysis, the methodology of calculations, appropriate boundary and beginning conditions as well as the structure and fluid properties were proposed. The calculations were performed in Ansys 16.2 [17].

The results presented in this paper may be useful in determining the urethra interaction with biomedical, biocompatible or biodegradable materials, including polymers as surrogates to restore a normal flow, which is a potential support for surgical practice and prosthesis design [40]. 


\section{Results}

The numerical task was focused on the observation of stress and strain fields of the urethral tissue (proximal part) in the micturition phase. On the basis of the numerical analysis carried out, graphs showing the characteristics of stress or deformation as a function of internal pressure were developed. Stress and strain of the Caucha tensor was studied. Figures 3 and 4 show deformations in the first and second direction respectively. The measurement was taken at the node on the edge of the urethra lumen where the deformation is the largest. The linear increase in pressure caused a very non-linear deformation of the urethra and the shape of the urethra lumen was aimed at a circular cross-section. The greatest deformation of the urethra occured where the wall thickness was lowest and the outer structure of the urethra was less deformed in relation to the interior. For the first strain of the Caucha tensor ( tension in radial direction) the maximum value was $1.17 \mathrm{~mm} / \mathrm{mm}$ at a maximum internal pressure of $4 \mathrm{kPa}$ (Fig.3).
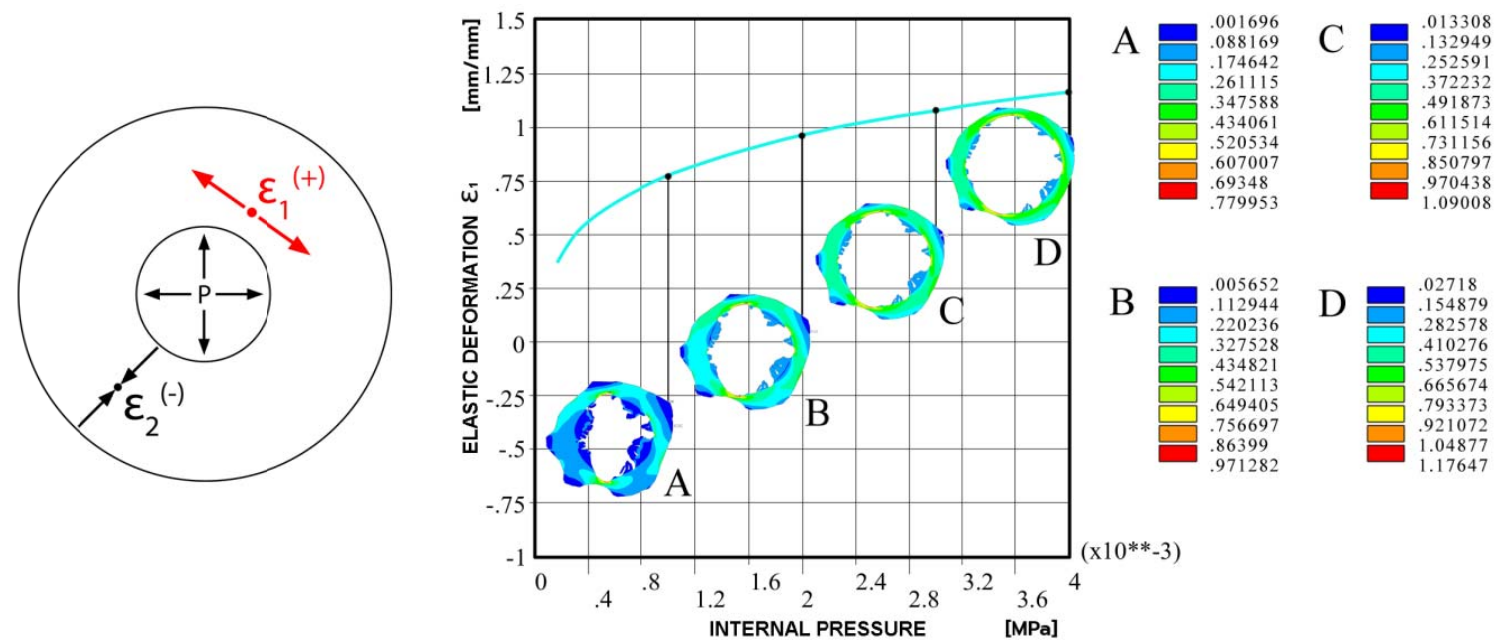

Fig.3. First deformation of the Caucha tensor as a function of pressure. A-D: selected phases of the urethra deformation.

In case of the second deformation of the Caucha tensor (compression in radial direction) the maximum value at the edge of the urethra lumen was $-0.55 \mathrm{~mm} / \mathrm{mm}$. The structures located in the central part directly affected by the internal pressure and in the zone where the thickness of the urethra structure was the lowest, which is visible in Fig.4 on individual sections, were compressed.
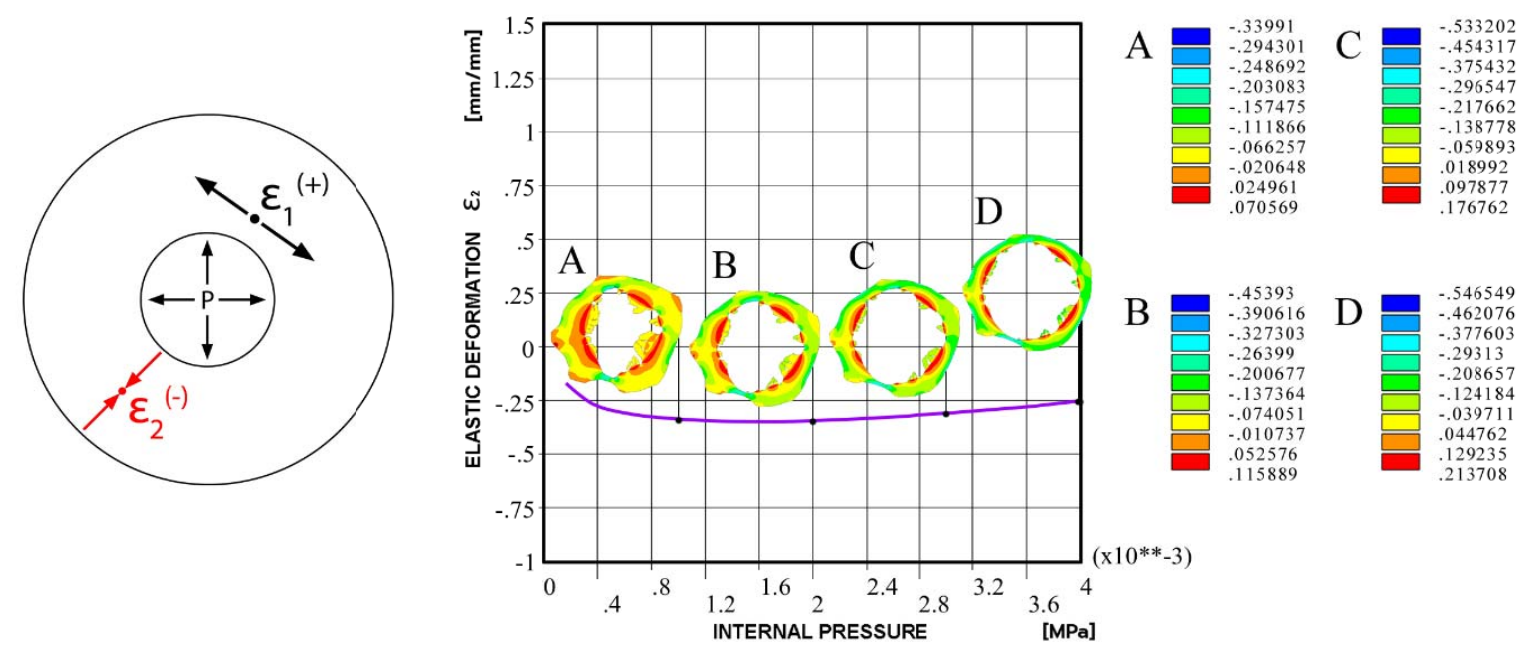

Fig.4. Second deformation of the Caucha tensor as a function of pressure. A-D: selected phases of the urethra deformation. 
Figure 5 shows the reduced strain and stress as a function of internal pressure. The maximum reduced strain von Mises of the urethra in the radial direction was $1.24 \mathrm{~mm} / \mathrm{mm}$ (Fig.6), while the maximum reduced strain von Mises did not exceed $9 \mathrm{kPa}$. The values obtained are similar to the scarce literature data. Differences in the results obtained and described in the literature are caused by different research subjects: horse urethra, etc. [32, 37, 39]. In case of the tests of Natali et al. [13, 39], the results of pressuredeformation dependence were given only for a range of elastic deformations not exceeding $0.6 \mathrm{~mm} / \mathrm{mm}$. It is worth noting that Natali used a tissue model of the equine urethra in his analysis. $[6,13]$. The urethra of White New Zealand rabbit has not yet been tested for reduced strain and stress. The test results presented in this paper will enable identification of the material model and stress-strain characteristics of the urethra. These results increase the knowledge of stress and strain fields, which can be used in further stages of work to study the dynamics of flow within high lyde formable tissues of the urethra and coupled fields in fluidstructure interaction in the urination phase.

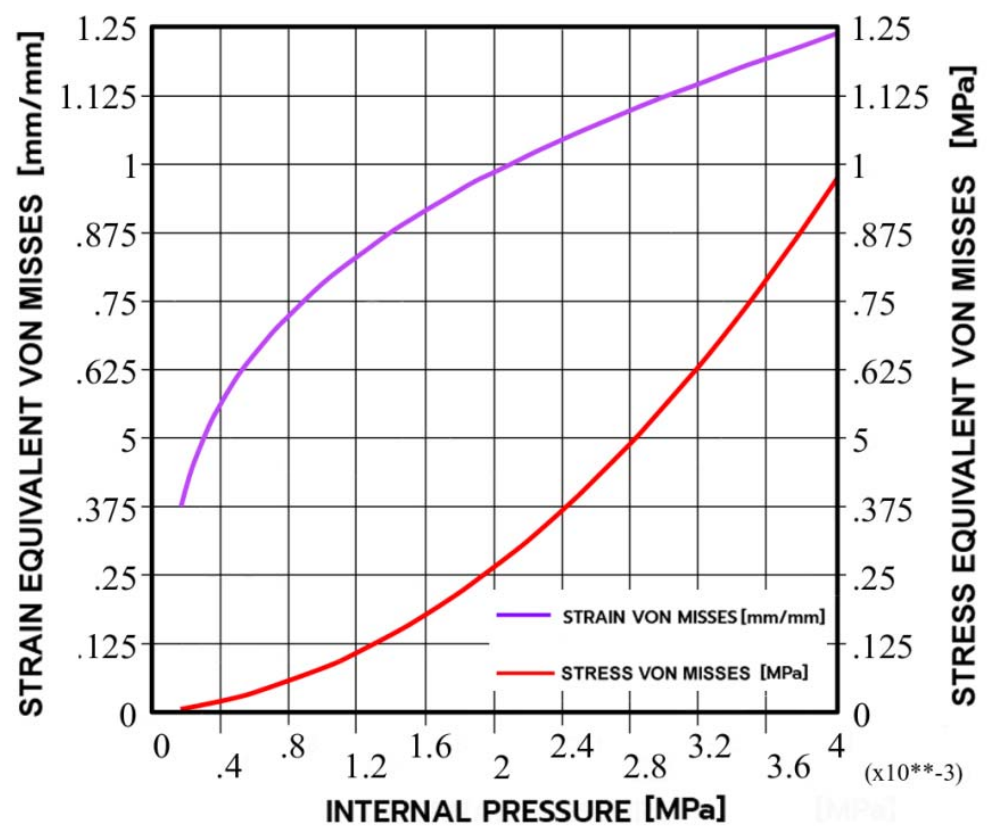

Fig.5. Reduced strain von Mises and reduced stress von Mises as a function of internal pressure.

The differences between the results presented in this work and those of other researchers result from different animal tissues, characteristics of individual models of hyper-elastic materials used for modelling. On the basis of the results obtained, a non-linear character of the material can be observed, which indicates its non-linear hyper-elastic properties. The urethra, as a tissue, deforms to a large extent despite a small internal pressure introduced (Fig.6). Under physiological conditions, the urethra additionally stabilises and stiffens the muscle structures and blood vessels surrounding the tissue. 


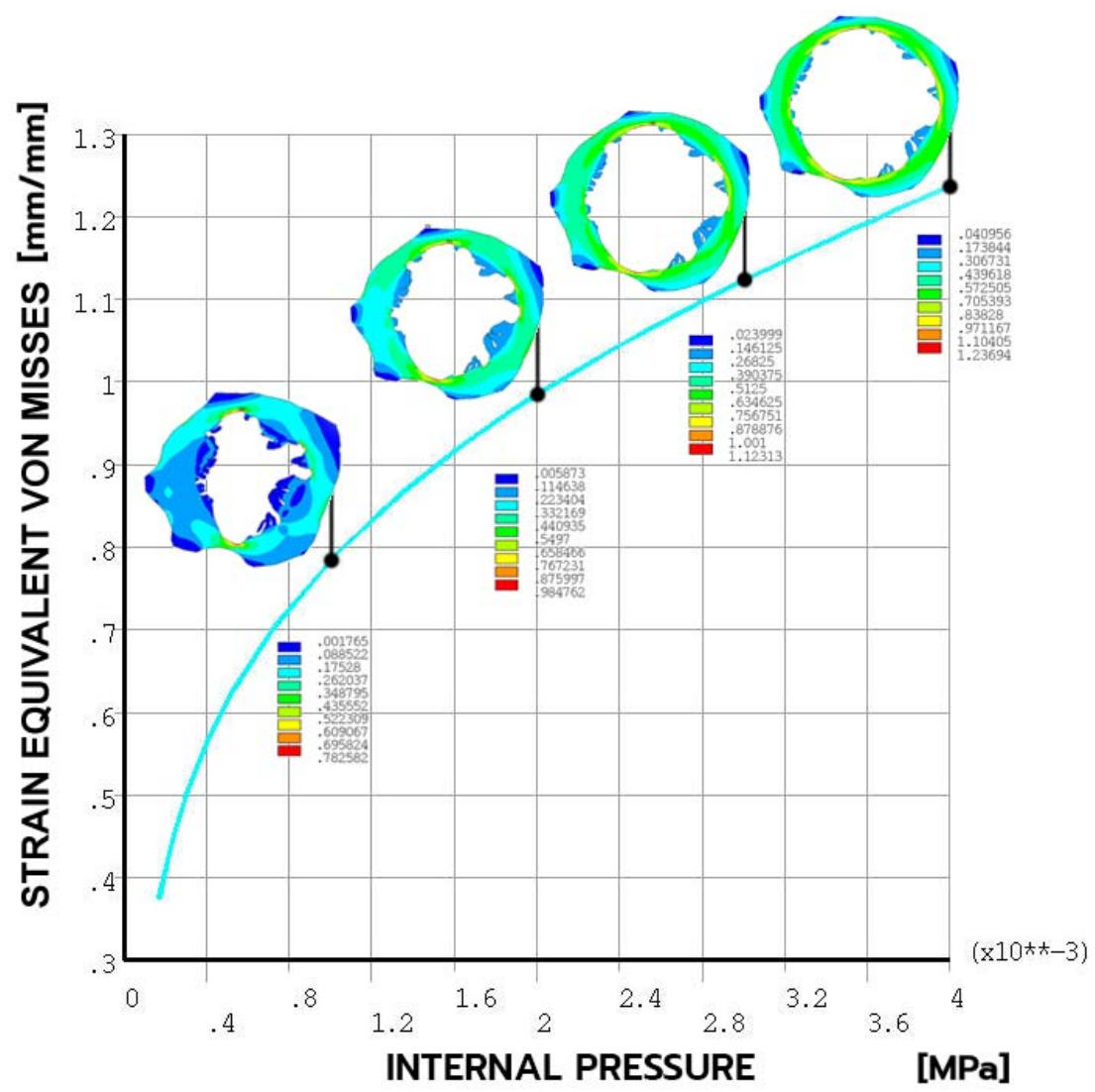

Fig.6. Reduced deformation von Mises for four selected phases of pressure increase.

\section{Discussion}

In the literature, there are many non-linear characterisation models of materials used in various studies describing mechanical properties of urethral material. The most frequently repeated are non-linear hyper-elastic or viscoelastic models. These models cause the urethra tissue to be deformed by the flow of urine without any major resistance until the maximum stiffness is reached [41]. Many authors have described stress-strain characteristics of the urethra by examining fragments of this organ during axial, radial and longitudinal tensile test (anisotropy or orthotropy) [6, 39, 42] or by simulating the fluid pressure on the urethra wall [39, 41, 43-45]. Modern research uses numerical models of the urethral structures (finite element method), but the basis for these models is still correct material data. Therefore, the authors of this publication carried out experimental research in order to complete the data for determining the mechanical properties of the urethra of White New Zealand rabbit. Numerical models were developed in which boundary conditions of undisturbed field of the urethra strain were applied and a model of 5-parameter Mooney-Rivlin material was adopted, which showed the best fit to the experimental results. The numerical model of the urethra was subjected to internal pressure resulting from the urine flow according to physiological conditions.

Studies of the mechanical properties of the human male urethra have shown that the maximum strain of 0.35 to $0.43 \mathrm{~mm} / \mathrm{mm}$ occurs during the urine flow at a pressure of $4 \mathrm{kPa}$ [32]. The strain results presented in this paper for the male rabbit, the maximum strain value for the same pressure is between $0.4-0.59$ $[\mathrm{mm} / \mathrm{mm}]$. The urethra of White New Zealand rabbit is very similar in stress-strain characteristics to that of the human urethra.

As a result of the analysis of the literature and the authors' own considerations, it was shown that the stress-strain characteristics of the urethra showed very non-linear characteristics. It is much more evident 
than in case of already well-studied blood vesselsand it applies to all the main directions of the urethra, especially to the first and second direction of the Caucha tensor [46, 47].

This has a significant impact on the ability to predict possible dysfunctions within the urinary system, including the development of elements to improve its functioning. The introduction of the replacement elements such as stents prevents the occurrence of discontinuity of the deformations caused by the flow disorders. The results presented by the authors of this study differ by no more than $20 \%$ from the results of other researchers, which results from different tissue structure even within the same species of animal model and different tissue anisotropy. It should be stressed that the results and conclusions obtained during this research are adequate to the ones achieved by the other authors [6, 39, 41, 43-45], however, experimental validation with possible modification of the characteristics is still an important element.

\section{Acknowledgments}

This investigation was supported by a research grant No DEC-2016/21/B/ST8/01972 financed by The National Science Centre. The protocol of the study was approved by the Local Ethics Committee in Wroclaw (decision No. 1/2017).

\section{Nomenclature}

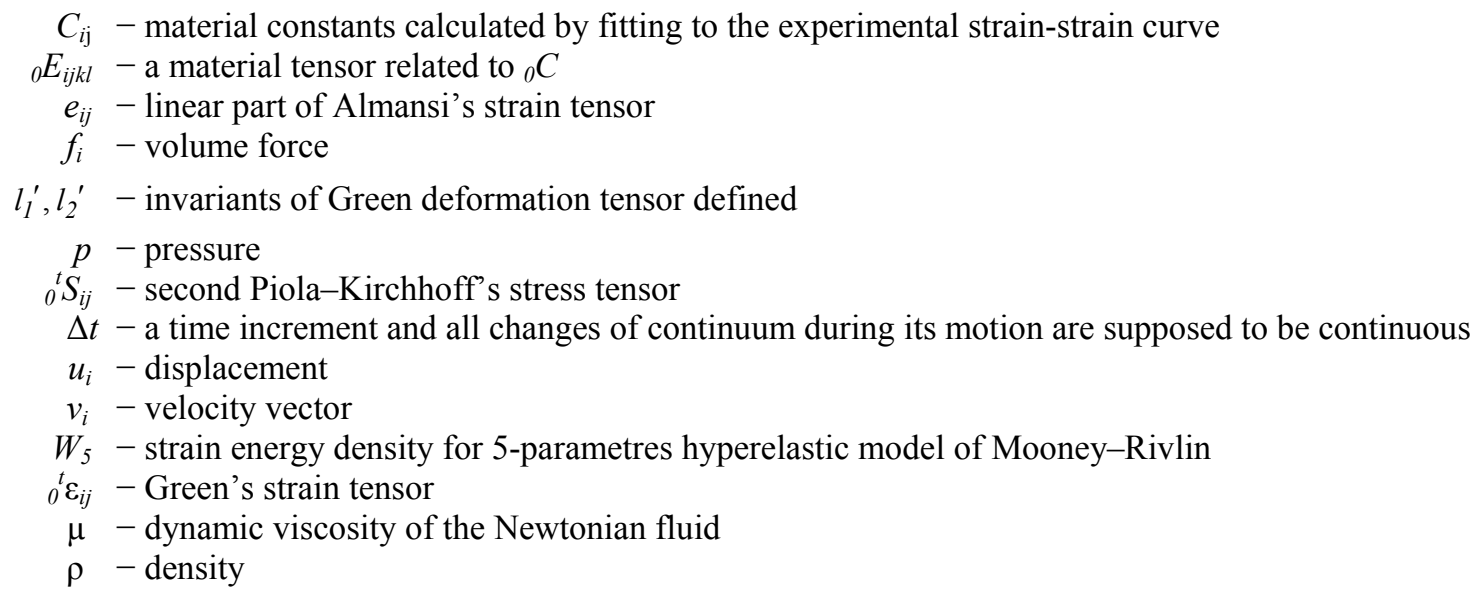

\section{References}

[1] Boselli F., Freund J.B. and Vermot J. (2015): Blood flow mechanics in cardiovascular development. - Cell Mol Life Sci., vol.72, No.13, pp.2545-2559.

[2] Halpern D. and Grotberg J.B. (2003): Nonlinear saturation of the Rayleigh instability in a liquid-lined tube due to oscillatory flow. - J. Fluid Mech., vol.492, pp.251-270.

[3] Dixon J.B., Gashev A.A., Zawieja D.C., Moore J.E. and Cote G.L. (2007): Image correlation algorithm for measuring lymphocyte velocity and diameter changes in contracting microlymphatics. - Ann Biomed Eng., vol.35, pp.387-396.

[4] Ishii T., Bys Y. and Ach Y. (2017): Vector flow visualization of urinary flow dynamics in a bladder outlet obstruction model. - Ultrasound Med Biol., vol.43, No.11, pp.2601-2610.

[5] Zamir M., Moore J.E., Fujioka H. and Gaver D.P. (2010): Biofluid mechanics of special organs and the issue of system control. - Ann Biomed Eng., vol.38, No.3, pp.1204-1215.

[6] Natali A.N., Carniel E.L., Fontanella C.G., Frigo A., Todros S., Rubini A., De Benedictis G.M., Cerruto M.A. and Artibani W. (2017): Mechanics of the urethral duct: tissue constitutive formulation and structural modeling for 
the investigation of lumen occlusion. - Biomechanics and Modeling in Mechanobiology, vol.16, No.2, pp.439447.

[7] Hampel C., Thuroff J.W. and Gillitzer R. (2010): Epidemiology and etiology of male urinary incontinence. Urologe, vol.49, pp.481-488.

[8] Mathur R., Aggarwal G., Satsangi B., Khan F. and Odiya S. (2011): Comprehensive analysis of etiology on the prognosis of urethral strictures. - International Braz. J. Urol., vol.37, No.3, pp.362-70.

[9] Nitti V.W. (2005): Pressure flow urodynamic studies: the gold standard for diagnosing bladder outlet obstruction. - Rev Urol., vol.7, Suppl 6, pp.S14-21.

[10] Cho K.S., Kim J.H., Kim D.J., Choi Y.D., Kim J.H. and Hong S.J. (2008): Relationship between prostatic urethral angle and urinary flow rate: its implication in benign prostatic hyperplasia pathogenesis. - Urology, vol.71, No.5, pp.858-62.

[11] Tritschler S., Roosen A., Füllhase C., Stief Ch.G. and Rübben H. (2013): Urethral stricture: etiology. investigation and treatments. - Dtsch Arztebl Int., vol.110, No.13, pp.220-226.

[12] Djordjevic, M. (2016),Treatment of urethral stricture disease by internal urethrotomy, dilation and stenting. European Urology, Suppl 15, pp. 7-12.

[13] Natali A., Carniel E., Fontanella C., Frigo A., Todros S., Rubini A., Benedictis G., Cerruto M. and Artibani W. (2016): Mechanics of the urethral duct: tissue constitutive formulation and structural modeling for the investigation of lumen occlusion. - Exp. Physiol., vol.101, No.5, pp.641-56.

[14] Chung E. (2014): A state-of-the-art review on the evolution of urinary sphincter devices for the treatment of postprostatectomy urinary incontinence: past, present and future innovations. - J. Med. Eng. Technol., vol.38, pp.328-332.

[15] Ramesh M.V., Raj D., Sanjeevan Kalavampra V. and Dilraj N. (2014): Design of wireless real time artificial sphincter control system for urinary incontinence. - IEEE Int. Symp. Technology Management and Emerging Technologies (ISTMET), Bandung, Indonesia, pp.44-49.

[16] Zhao L. (2017): Male urethral reconstruction and the management of urethral stricture disease. - Urologic Clinics of North America, vol.44, No.1, pp.1-146.

[17] Cohen A.J., Baradaran N., Mena J., Krsmanovich D. and Breyer B.N. (2019): Computational fluid dynamic modeling of urethral strictures. - J. Urol., vol.202, No.2, pp.347-353.

[18] Jin Q., Zhang X., Li X. and Wang J. (2010): Dynamics analysis of bladder-urethra system based on CFD. - Front. Mech. Eng., vol.5, No.3, pp.336-340.

[19] Bonfanti M., Balabani S., Alimohammadi M., Agu O., Homer-Vanniasinkam S. and Díaz-Zuccarini V. (2018): $A$ simplified method to account for wall motion in patient-specific blood flow simulations of aortic dissection: comparison with fluid-structure interaction. - Medical Engineering and Physics, vol.58, pp.72-79.

[20] Zheng J., Pan J., Qin Y., Huang J., Luo Y., Gao X. and Zhou X. (2015): Role for intravesical prostatic protrusion in lower urinary tract symptom: a fluid structural interaction analysis study. - BMC Urology, vol.15, Article No.86.

[21] Tuccitto G., Benjamin F., Maccatrozzo L., Santoro G.A., Wieczorek A.P. and Bartram C.I. (2010): Urodynamics Edoardo Ostardo. - Pelvic Floor Disorders Springer-Verlag Italia.

[22] Zhang K., Fu Q., Yoo J., Chen X., Chandra P., Moc X., Song L., Atala A. and Zhao W. (2016): 3D bioprinting of urethra with PCL/PLCL blend and dual autologous cellsin fibrin hydrogel: An in vitro evaluation of biomimetic mechanicalproperty and cell growth environment. - Acta Biomaterialia, vol.43, pp.154-164.

[23] Zinner R., Sterling A.M., Ritter R.C., Harris J.H., Gessner B.F., Reid J.M., Hedges J., Chow D. and Barber E.F. (1973): The Velocity Profile of the Human urethra: Measurement and Significance N., Urodynamics (C) SpringerVerlag Berlin Heidelberg.

[24] Bréaud J., Baqué P., Loeffler J., Colomb F., Brunet C. and Thollon L. (2012): Posterior urethral injuries associated with pelvic injuries in young adults: computerized finite element model creation and application to improve knowledge and prevention of these lesions. - Surg. Radiol. Anat., vol.34, No.4, pp.333-339. 
[25] Spirka T., Kenton K., Brubaker L. and Damaser M.S. (2013): Effect of material properties on predicted vesical pressure during a cough in a simplified computational model of the bladder and urethra. - Ann Biomed Eng., vol.41, No.1, pp.185-194.

[26] Bush M.B., Lied B. and Petros P.R. (2014): A finite element model validates an external mechanism for opening the urethral tube prior to micturition in the female. - World J. Urol., vol.33, No.8, pp.1151-1157.

[27] Shi L.B., Cai H.X., Chen L.K., Wu Y., Zhu S.A., Gong X.N., Xia Y.X., Ouyang H.W. and Zou X.H. (2014): Tissue engineered bulking agent with adipose-derived stem cells and silk fibroin microspheres for the treatment of intrinsic urethral sphincter deficiency. - Biomaterials, vol.35, No.5, pp.1519-1530.

[28] Tai H., Yin J-H., Huang Z-H. and Tsao T-Y. (2015): Penile-preserving surgery for primary urothelial carcinoma of male urethra. - Urological Science, vol.26, No.2, pp.131-133.

[29] Jia W., Tang H., Wu J., Hou X., Chen B., Chen W., Zhao Y., Shi C., Zhou F., Yu W., Huang S., Ye G. and Dai J. (2015): Urethral tissue regeneration using collagen scaffold modified with collagen binding VEGF in a beagle model. - Biomaterials, vol.69, pp.45-55.

[30] Skonieczna J., Madej J.P. and Będziński R. (2019): Accessory genital glands in the New Zealand white rabbit: A morphometrical and histological study. - J. Vet. Res., vol.63, No.2, pp.251-257.

[31] Holzapfel G.A. (2001): Biomechanics of soft tissue. - In: Lemaitre J (ed) Handbook of Materials Behavior Models. Academic Press, USA, pp.1057-1070.

[32] Müller B., Ratia J.G, Marti F., Leippold T. (2008), Mechanical properties of tissue urethral - Journal of Biomechanics, 41 Supplement 1, pp. S61.

[34] Horák M. and Kren J. (2003): Mathematical model of the male urinary tract. - Mathematics and Computers in Simulation, vol.61, pp.573-581.

[35] Kumar N. and Rao V. (2016): Hyperelastic Mooney-Rivlin Model: Determination and physical interpretation of material constants. - MIT International Journal of Mechanical Engineering, vol.6, No.1, pp.43-46.

[36] Barzegari M., Vahidi B. and Safarinejad M.R. (2017): A Clinical and Finite Elements Study of Stress Urinary Incontinence in Women Using Fluid-Structure Interactions. - Project: Computational Analysis of Stress Urinary Incontinence.

[37] Zheng Q., Ding Ch., Sun B., Li Y., Sun X. and Zhao Ch. (2013): Establishment of a stable urethral stricture model in New Zealands rabbits. - Actas Urológicas Españolas, vol.37, No.3, pp.162-166.

[38] Andersen H.L., Duch B.U., Gregersen H., Nielsen J.B. and Ørskov H.(2003): The effect of the somatostatin analogue Lanreotide on the prevention of urethral strictures in a rabbit model. - Urol. Res., vol.31, pp.25-31.

[39] Natali A., Carniel E., Frigo A., Pavan P., Todros S., Pachera P., Fontanella C., Rubini A., Cavicchioli L., Avital Y. and Benedictis G. (2016): Experimental investigation of the biomechanics of urethral tissues and structures. Exp. Physiol, 101.5, pp.641-656.

[40] Kaczmarek-Pawelska A. (2019): Based hydrogels in regenerative medicine. - In Alginates, ed. L. Pereira. J. Cotas, IntechOpen Limited, pp.1-16.

[41] Bagi P., Thind P., Colstrup H. and Kristensen J.K. (1993): The dynamic pressure response to rapid dilatation of the resting urethra in healthy women: an in vivo evaluation of visco-elastic properties. - Urol. Res., vol.21, No.5, pp.339-43.

[42] Todros S., Pavan P.G. and Natali A.N. (2016): Biomechanical properties of synthetic surgical meshes for pelvic prolapse repair. - J. Mech. Behav. Biomed. Mater., vol.55, pp.271-285.

[43] Yao F., Laudano M.A., Seklehner S., Chughtai B. and Lee R.K. (2015): Image-based simulation of urethral distensibility and flow resistance as a function of pelvic floor anatomy. - Neurourol. Urodyn., vol.34, No.7, pp.664-668.

[44] Jankowski R.J., Prantil R.L., Fraser M.O., Chancellor M.B., De Groat W.C., Huard J. and Vorp D.A. (2004): Development of an experimental system for the study of urethral biomechanical function. - Am J. Physiol. Renal. Physiol, vol.286, No.2, pp.225-322. 
[45] Korkmaz I. and Rogg B. (2007): A simple fluid-mechanical model for the prediction of the stress-strain relation of the male urinary bladder. - J. Biomech., vol.40, No.3, pp.663-668.

[46] Jankowska M.A., Bartkowiak-Jowsa M. and Będziński R. (2015): Experimental and constitutive modeling approaches for a study of biomechanical properties of human coronary arteries. - Journal of the Mechanical Behavior of Biomedical Materials, vol.50, pp.1-12.

[47] Bartkowiak-Jowsa M., Będziński R., Szaraniec B. and Chlopek J. (2011): Mechanical, biological, and microstructural properties of biodegradable models of polymeric stents made of PLLA and alginate fibers. - Acta of Bioengineering and Biomechanics, vol.13, pp.21-28.

Received: February 12, 2020

Revised: April 15, 2020 